\title{
THE EFFECT OF HYDROGEN PRESSURE ON THE HYDROGENATION REACTION OF COAL
}

\author{
Yosuke MAEKAWA, TADAo ISHII and Gen TAKEYA \\ Government Industrial Development Laboratory, Hokkaido, \\ Sapporo 061-01
}

\begin{abstract}
The hydrogenolysis of Sumiyoshi coal was studied at $400^{\circ} \mathrm{C}$ under the reaction pressure of 110 to $220 \mathrm{~atm}$. The reaction rate constant was calculated from the rate of decrease of unreacted coal. The data obtained were expressed as a first order reaction consisting of two steps. The rate constant in the second step increased linearly with the hydrogen pressure. But the rate constant of the direct production of oil from coal in the first step was almost constant.
\end{abstract}

\section{Introduction}

Coal liquefaction is generally conducted with vehicle oil and catalyst under high temperature and high hydrogen pressure. A hydrogen pressure of 220$700 \mathrm{~atm}$ is required to obtain a practical liquefaction rate.

Regarding the effect of hydrogen pressure on the liquefaction of coal, much experimental work has been conducted in $\mathrm{Japan}^{4,6)}$ and abroad ${ }^{2,3)}$ in the past. These earlier studies were mainly concerned with the yields and properties of oil produced by the secondary decomposition of primary liquefaction products.

A quantitative investigation was undertaken by Pelipetz et $a l_{0}{ }^{8)}$ to determine the effect of hydrogen pressure on the so-called primary reaction in which coal was converted into benzene-soluble products by hydrogenolysis. Consequently, it was reported that the reaction rate constant increased linearly with the reaction pressure.

The hydrogenolysis of American coal used in their studies was expressed as a one-step first order reaction $^{1)}$, while in the case of Japanese coal the hydrogenolysis was expressed as a first order reaction consisting of two steps ${ }^{5)}$. It can therefore be presumed that the effect of reaction pressure on Japanese coal differ from that shown in American coals.

In the present paper the high-pressure hydrogenolysis of Japanese coal was carried out under various reaction pressures, and the reaction rate constants were measured to investigate the effect of hydrogen pressure on the liquefaction of coal.

\section{Experimental}

Sumiyoshi coal which is a brown coal produced in Hokkaido was used. The ultimate and proximate

Received July 12, 1976 . Correspondence concerning this article should be addressed to Y. Maekawa. T. Ishii is at Faculty of Eng., Hokkaido Univ., Sapporo 060. G. Takeya is at Hakodate Technical College, Hakodate 042 . analyses of the coal are presented in Table $\mathbf{1}$.

The experiments were conducted in a shaking type autoclave with an internal volume of $500 \mathrm{~m} l$. In all runs, $10 \mathrm{~g}$ of dried coal pulverized to a uniform size under 100 mesh, $15 \mathrm{~g}$ of decrystallized anthracene vehicle oil, $1 \mathrm{~g}$ of red-mud catalyst, $0.1 \mathrm{~g}$ of sulfur promoter and 10 steel balls for agitation $(16 \mathrm{~mm}$ diameter) were charged into the autoclave.

The initial hydrogen pressure charged was 50,70 and $100 \mathrm{~atm}$ and its reaction pressure was approximately 110,160 and 220 atmospheres at $400^{\circ} \mathrm{C}$ reaction temperature. Under each reaction pressure the hydrogenolysis of Sumiyoshi coal was carried out with a nominal reaction time of zero to 123 minutes. The autoclave was heated to the reaction temperature at a rate of about $3^{\circ} \mathrm{C} / \mathrm{min}$. and the nominal reaction time was calculated from the time when the temperature attained a given reaction temperature.

The reaction products were subjected to $n$-hexane extraction by a Soxhlet extractor, followed by benzene extraction, and then the oil ( $n$-hexane solubles + produced gas + water), asphaltene ( $n$-hexane insoluble and benzene soluble material) and unreacted coal (organic benzene insolubles) were separated and weighed. The conversion is calculated from the yield of organic benzene insolubles.

The decrease rate of organic benzene-insolubles was taken as the rate of coal liquefaction by hydrogenolysis.

\section{Experimental Results and Discussions}

The reaction conditions of hydrogenolysis and the yields of various reaction products and conversion

\begin{tabular}{lllllllll}
\hline \multicolumn{1}{c}{ Table 1 } & \multicolumn{1}{c}{ Analysis of Sumiyoshi coal } \\
\multicolumn{4}{c}{ Proximate analysis } & Ultimate analysis \\
$\mathrm{H}_{2} \mathrm{O}$ & Ash & V.M. & F.C. & $\mathrm{C}$ & $\mathrm{H}$ & $\mathrm{N}$ & $\mathrm{S}$ & $\mathrm{O}^{*}$ \\
6.2 & 6.9 & 47.8 & 39.1 & 75.5 & 6.2 & 1.2 & 0.4 & 16.7 \\
$*$ & by difference & & & & & & \\
\hline
\end{tabular}


Table 2 Results of experiment of Sumiyoshi coal hydrogenolysis under various hydrogen pressure

\begin{tabular}{|c|c|c|c|c|c|c|}
\hline \multicolumn{3}{|c|}{ Experimental conditions } & \multicolumn{4}{|c|}{ Products and conversion* } \\
\hline $\begin{array}{l}\text { React. pressure } \\
\text { [atm] }\end{array}$ & $\begin{array}{c}\text { React. time } \\
\text { [min] }\end{array}$ & $\begin{array}{l}\text { React. temp. } \\
\left.\qquad{ }^{\circ} \mathrm{C}\right]\end{array}$ & $\begin{array}{c}\text { Oil (and gas, } \\
\text { water) } \\
{[\%]}\end{array}$ & $\begin{array}{c}\text { Asphaltene } \\
{[\%]}\end{array}$ & $\begin{array}{c}\text { Organic } \\
\text { benzene } \\
\text { insolubles }[\%]\end{array}$ & $\begin{array}{c}\text { Conversion } \\
{[\%]}\end{array}$ \\
\hline $110-112$ & 7 & $400-400$ & 30.3 & 16.1 & 53.6 & 46.4 \\
\hline $111-112$ & 20 & $400-405$ & 40.8 & 19.7 & 39.5 & 60.5 \\
\hline $110-114$ & 83 & $388-407$ & 55.1 & 17.2 & 27.7 & 72.3 \\
\hline $109-112$ & 120 & $391-408$ & 55.8 & 22.2 & 22.0 & 78.0 \\
\hline $160-161$ & 21 & $400-401$ & 40.6 & 31.2 & 28.2 & 71.8 \\
\hline $159-162$ & 43 & $396-405$ & 42.7 & 33.9 & 23.4 & 76.6 \\
\hline $160-164$ & 83 & $398-406$ & 48.0 & 35.0 & 17.0 & 83.0 \\
\hline $220-222$ & 5 & $400-403$ & 37.5 & 21.0 & 41.5 & 58.5 \\
\hline $221-223$ & 22 & $395-402$ & 48.3 & 24.9 & 26.8 & 73.2 \\
\hline $219-221$ & 34 & $400-402$ & 51.4 & 32.8 & 15.8 & 84.2 \\
\hline $231-236$ & 40 & $400-402$ & 45.9 & 36.6 & 17.5 & 82.5 \\
\hline $220-224$ & 63 & $396-404$ & 55.5 & 28.8 & 15.7 & 84.3 \\
\hline $228-232$ & 102 & $396-408$ & 66.1 & 23.8 & 10.1 & 89.9 \\
\hline $216-221$ & 123 & $396-404$ & 71.5 & 20.4 & 8.1 & 91.9 \\
\hline
\end{tabular}

* d. a. f. coal basis

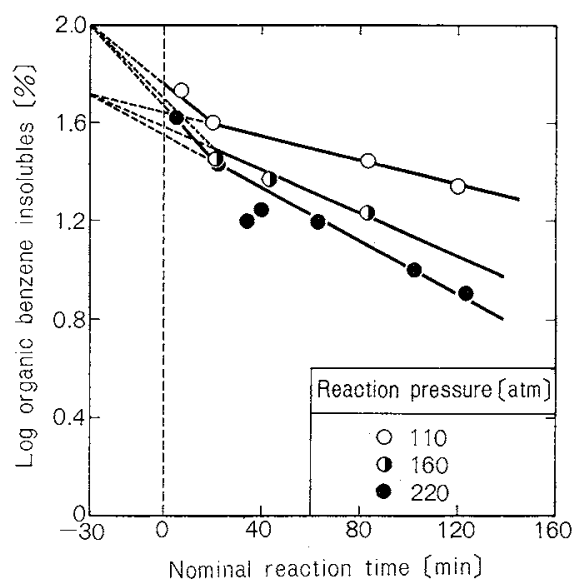

Fig. 1 Conversion of Sumiyoshi coal plotted as a first order reaction

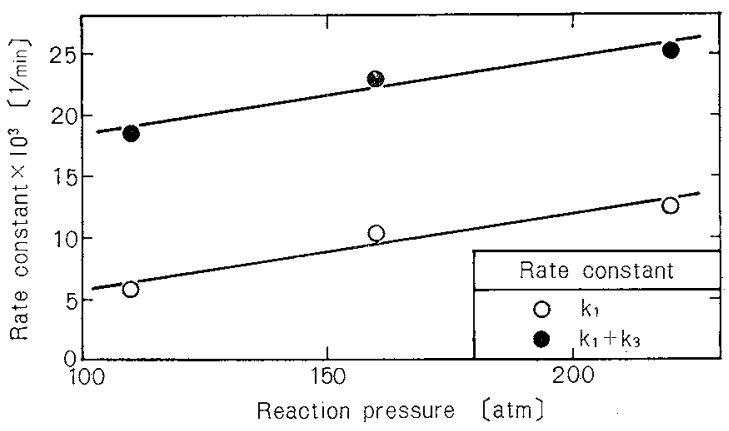

Fig. 2 Relationship between reaction pressure and rate constants at $400^{\circ} \mathrm{C}$

are summarized in Table 2. As the hydrogenolysis reaction proceeded even during heating up and cooling down of autoclave, a correction time must be added to the nominal reaction time. It was calculated as 30 minutes for Sumiyoshi coal ${ }^{5}$. Considering this correction time, experimental results were plotted as a first order reaction in Fig. 1. From Fig. 1, it was found that the reaction mechanisms were the same even
Table 3 Reaction rate constants $\left(\mathrm{min}^{-1}\right)$ for Sumiyoshi coal hydrogenation at $400^{\circ} \mathrm{C}$

\begin{tabular}{lccc} 
& \multicolumn{3}{c}{ Reaction pressure [atm] } \\
Reaction step & 110 & 160 & 220 \\
\hline 1st $\left(k_{1}+k_{3}\right)$ & 0.0184 & $(0.0230)^{*}$ & 0.0253 \\
2nd $\left(k_{1}\right)$ & 0.0058 & 0.0102 & 0.0125 \\
$\quad k_{3}$ & 0.0126 & $(0.0128)^{*}$ & 0.0128 \\
* The estimated values & & \\
\hline
\end{tabular}

under different reaction pressures as previously report$\mathrm{ed}^{5)}$, and that the data obtained were expressed as a first order reaction consisting of two steps. By extrapolating the second step reactions under different pressures to -30 minutes of nominal reaction time, it was found that these lines intersected at the same point on the longitudinal axis. This shows that the correction time is not affected by reaction pressure. Therefore, above assumption may be considered to be correct.

On the basis of the reaction mechanism obtained by the hydrogenolysis of Japanese coals ${ }^{7,8)}$ the reaction in the second step was found to be attributed to hydrogenolysis of the main part of coal, and a successive decomposition of coal to oil via asphaltene was expressed in Eq. (2). In the first step a rapid, direct production of oil from coal as shown in Eq. (1) proceeded in parallel with Eq. (2).

$$
\begin{aligned}
& \operatorname{Coal}(A) \stackrel{k_{3}}{\longrightarrow} \operatorname{oil}\left(S_{1}\right) \\
& \operatorname{Coal}(A) \stackrel{k_{1}}{\longrightarrow} \text { asphaltene }(R) \stackrel{k_{2}}{\longrightarrow} \operatorname{oil}\left(S_{2}\right)
\end{aligned}
$$

Table 3 shows the reaction rate constants calculated from the straight line gradient in Fig. 1. From Table 3 , it was found that the rate constant, $k_{3}$, of the direct decomposition of coal to oil in the first step was almost constant and therefore this reaction was not affected by the pressure of hydrogen in the range of 110 to 220 atm. Figure 2 shows the relationship between the reaction pressure and the rate constant, $k_{1}$ and $\left(k_{1}+k_{3}\right)$. 
It was recognized that the value of rate constant showed an approximate linear increase with the reaction pressure and was expressed in Eq. (3).

$$
k_{1}=5.8 \times 10^{-5} P+C
$$

\section{Conclusion}

1) Under a reaction pressure of $110-220$ atm the hydrogenolysis of Sumiyoshi coal consisted of two steps and both steps could be expressed as a first order reaction, as hitherto reported for 220 atmospheres. 2) The reaction rate constant, $k_{1}$, in the second step increased linearly with the hydrogen pressure and was expressed in the equation of $k_{1}=5.8 \times$ $10^{-5} P+C$. 3) The reaction rate constant, $k_{3}$, was regarded as almost constant under these reaction pressures.

\section{Nomenclature}

C $=$ constant $\quad[-]$

$C_{A}=$ concentration of coal $[\mathrm{g} / \mathrm{g}]$

$\begin{array}{lll}C_{R} & =\text { concentration of asphaltene } \quad[\mathrm{g} / \mathrm{g}]\end{array}$

$k_{1} \quad=$ reaction rate constant from coal to asphaltene

$[1 / \mathrm{min}]$

$k_{2} \quad=$ reaction rate constant from asphaltene to oil $\left(S_{2}\right)$

$[1 / \mathrm{min}]$

$k_{3} \quad=$ reaction rate constant from coal to oil $\left(S_{1}\right)[1 / \mathrm{min}]$

$P \quad=$ reaction pressure [atm]

\section{Literature Cited}

1) Falkum, E. and R. A. Glenn: Fuel, 31, 133 (1952).

2) Graham, J. I.: ibid., 7, 549 (1928).

3) Hirst, L. L. et al.: Ind. Eng. Chem., 31, 869 (1939).

4) Ishikawa, S., K. Yamagata, K. Morikawa and R. Ave: Kogyo Kagaku Zasshi (J. Chem. Soc. Japan, Industrial Chemistry Section), 44, 383 (1941).

5) Ishii, T., Y. Maekawa and G. Takeya: J. Chem. Eng. Japan, 4, 184 (1966).

6) Kurokawa, M.: Kogyo Kagaku Zasshi (J. Chem. Soc. Jpn., Industrial Chemistry Section), 46, 1301 (1943).

7) Maekawa, Y., K. Shimokawa, T. Ishii and G. Takeya: $J$. Fuel Soc. Jpn., 46, 927 (1967).

8) Pelipetz, M. G., J. R. SaImon, J. Bayer and E. L. Clark: Ind. Eng. Chem., 45, 806 (1953).

9) Yoshida, R., Y. Mackawa, T. Ishii and G. Takeya: Nippon Kagaku Kaishi (J. Chem. Soc. Jpn., Chemistry and Industrial Chemistry), 1972, 1885. 